\title{
RADIO FREQUENCY IDENTIFICATION BASED LIBRARY MANAGEMENT SYSTEM
}

\author{
Priyanka Grover and Anshul Ahuja \\ Information Technology Engg. \\ Lingaya's Institute of Mngt. \& Tech, \\ India \\ priyanka_grover88@yahoo.co.in, anshul1311@yahoo.com
}

\begin{abstract}
Radio frequency identification (RFID) is a term that is used to describe a system that transfers the identity of an object or person wirelessly, using radio waves. It falls under the category of automatic identification technologies. This paper proposes RFID Based Library Management System that would allow fast transaction flow and will make easy to handle the issue and return of books from the library without much intervention of manual book keeping. The proposed system is based on RFID readers and passive RFID tags that are able to electronically store information that can be read with the help of the RFID reader. This system would be able to issue and return books via RFID tags and also calculates the corresponding fine associated with the time period of the absence of the book from the library database.
\end{abstract}

Keywords- Radio frequency identification technology; RFID Readers; RFID Tags; Inductive Coupling

\section{I - INTRODUCTION}

Radio-frequency identification (RFID) is an automatic identification method, which can store and remotely retrieve data using devices called RFID tags. [1] The technology requires cooperation of RFID reader and RFID tag. The RFID based LMS facilitates the fast issuing, reissuing and returning of books with the help of RFID enabled modules. It directly provides the book information and library member information to the library management system and does not need the manual typing. This technology has slowly begun to replace the traditional barcodes [8] on library items and has advantages as well as disadvantages over existing barcodes [2].The RFID tag can contain identifying information, such as a book's title or code, without having to be pointed to a separate database. The information is read by an RFID reader, which replaces the standard barcode reader commonly found at a library's circulation desk. For which utmost care has been taken to remove manual book keeping of records, reduce time consumption as line of sight and manual interaction are not needed for RFID-tag reading and improve utilization of resources like manpower, infrastructure etc.

The remainder of this paper is organized into following sections:

Section 2 briefly reviews the concept of RFID technology, components of RFID and operating principles of these systems; Section 3 gives the details of the methodology used for implementing the system; Sector 4 draws the conclusion about the robustness of the technology.

\section{Background and Related Work}

There is a boom in the industry to use RFID technology in the recent years. Research and development in this field has made this technology to be used in supply chain management, attendance management, library management, automated toll collection etc.

There are multiple RFID standards being used in the industry. The existence of these multiple standards helps the users of this technology to choose between various standards and choose the approach which best suits them and then implement it for communication between an interrogator (RFID reader) and the RFID tag.

In more specific terms relating RFID to library, RFID in libraries was first developed and was proposed to the world in the late 1990s. RFID technology aimed at increasing the overall workflow in the library to the maximum as possible and to make everything like book issuing to book returning automatic. Singapore [4] was the first country to introduce RFID in libraries and the Rockefeller University in New York was the first academic library in the U.S to make use of this technology. Farmington Community Library was the first public institution to use the RFID technology. Both Rockefellers University and Farmington started using RFID in 1999. In Europe, the first public library to use RFID is the Hoogezand-Sappemeer, the Netherlands, in 2001, where borrowers were given options. It was proved in a survey that $70 \%$ people adapted to the RFID technology quickly.

Overall, RFID technology is used in United States the most and then in United Kingdom and then in Japan.

But there is an issue that this technology is still costly in today's market for the smaller organizations as compared to the larger organizations.

\section{II - LOGIC BEHIND THE SYSTEM}

\section{A. Concept}

The concept [6][7] of RFID can be viewed as an extension to electronic barcode[8], which can be used to identify, track, 
or detect holdings in the daily maintenance of library. This system, consist of smart RFID tags, that provides libraries with more effective way of managing their collections while providing greater customer service to their users. The technology works on small and thin tags, which allows it to be placed on the inside cover of each book in a library's collection. The tag consists of an antenna and a tiny chip which stores small amount of data to identify each item. These tags are applied directly on library books and can be read with a RFID Reader. Line of sight is not essential for reading the tags with the reader, therefore, the books require much less human handling to be read and processed. Server software integrates the reader hardware with the Library Automation Software for seamless functioning of book keeping. The information contained on microchips in the tags affixed to library materials is read using radio signals regardless of item orientation or alignment. It provides a wireless data link, without need for line of sight. In addition to tags, an RFID system requires a means for reading or "interrogating" the tags to obtain the stored data and then some means of communicating this tag data to library information system. RFID tag's listen for a radio query from the reader and respond by transmitting their unique ID code. When the data stored in the chip inside the tag is transmitted to the reader, the reader stores this data in a log file. This log file is read by the Server's Library Automation Software and this data is, in turn, stored in the database that resides in the server.

\section{B. Components}

RFID system consists of following four components [2]:
- $\quad$ RFID tags
- RFID readers
- Antenna
- Server

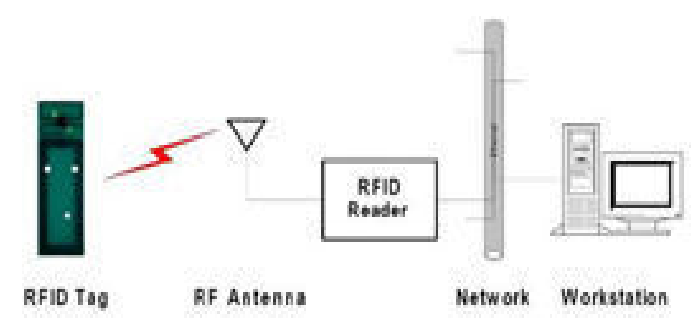

Figure 1. RFID Components

RFID Tags: Tags are thin labels which can be fixed inside a book's back cover. RFID tags are made up of carbonic structure which contains a magnetic strip or coil layer inside the tag which helps in sensing the tags. This magnetic layer inside the tag helps in generating the magnetic field. In the figure shown, the tag contains a unique serial number like
"0600394791 000345" which is used for the authentication of the user.

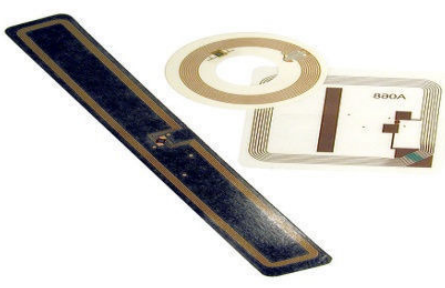

Figure 2. RFID Tags

When we bring the tag in front of the reader or in a close proximity of the reader, the reader antenna senses the tag and checks for the unique serial number of the tag. If the tag is registered in the reader's database then the reader authenticates the tag otherwise the reader shows an error and gives the message that the tag is not registered or the tag is not authenticated.

There are three types of tags: read only, WORM, and $\mathrm{read} /$ write. Tags are "read only" if the identification is encoded at the time of manufacture and not rewritable. "WORM" (Write-Once-Read-Many) tags are programmed by the using organization, but without the ability to rewrite the data in them later. "Read/write tags," provides the ability to change existing information in the tag or to add new information in it when some editing is needed.

RFID Readers: RFID readers are used to interrogate data stored in tags. It contains a radio frequency module, a control unit and an antenna to interrogate electronic tags via radio signals. The antenna inside the reader generates electromagnetic field. When a tag passes through the field, the information stored on the chip in the tag is interpreted by the reader and sent to the server, which, in turn, stores or retrieves information about the book's issue or return.

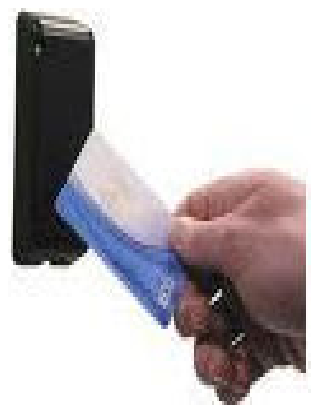

Figure 3. RFID Reader

Antenna: The antenna resides inside the reader. It generates electromagnetic field. Whenever a tag comes in close proximity of the electromagnetic field it gets activated and it is able to read and write data to the reader by producing radio signals. Antenna behaves like a communication media between the tag and the reader. 
Server: Server is a computer that contains a database where information related to book's issue and return are stored and this information can be retrieved when needed. Server connected to the reader via a cable. It receives information from the readers when the tag is brought in close proximity of the reader.

\section{Operating Principle}

Inductive Coupling: Inductive Coupling is the transfer of energy from one circuit to another through a shared magnetic field which is produced due to mutual inductance between two circuits. In RFID systems based on inductive coupling, the reader antenna and the tag antenna each consists of a coil. An electric current passing through the coil of reader's antenna generates a magnetic field that induces an electric current in the coil present in the tag which is exposed to that field. Inductively coupled tags are said to be operated passively because all the energy required to activate the tag is provided by the reader. Tag does not contain any source for power supply to activate itself. When the tag is in the close proximity of the reader, the magnetic field emitted by the reader penetrates the coil of the tag. The tag then takes energy from this filed. By mutual inductance between the tag and the reader, a voltage is generated in the tag's coil. This voltage serves as the power supply for the microchip carrying the data which is present inside the tag. This voltage is used by the microchip to change the electrical load on the tag antenna. These changes are recorded by the reader antenna and are converted into a unique serial number. This data is stored in the reader's $\log$ file as the data read from the tag. Server connected to the reader then takes up this data for processing through Library Automation System.

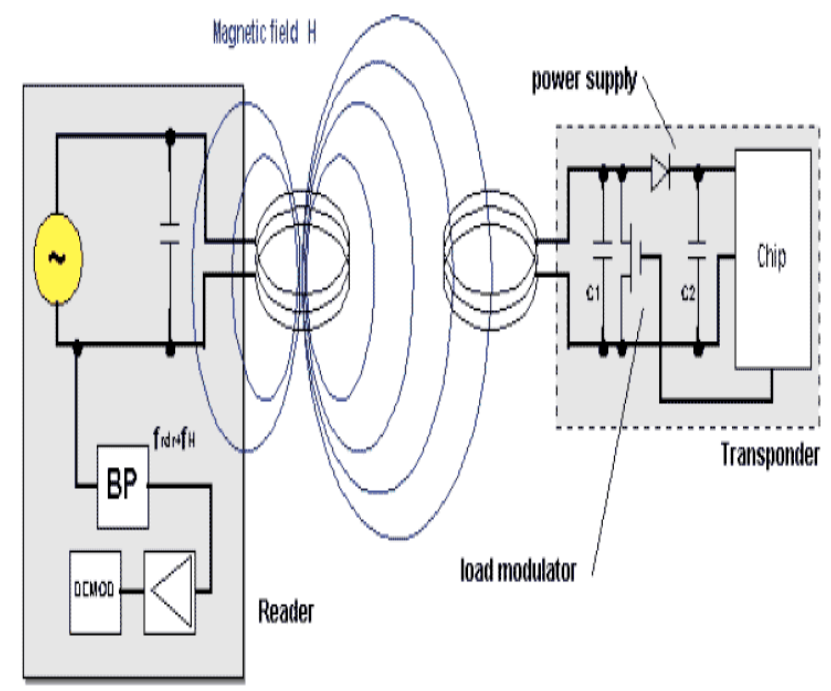

The above figure describes inductive coupling [9] [10]. A capacitor is connected in parallel with the reader's antenna coil. The capacitor has capacitance such that it is compatible with the coil inductance of the antenna coil to form a parallel resonant circuit, with a resonant frequency that corresponds with the transmission frequency of the reader. The resonance step-up in the parallel resonant circuit generates high current in the antenna coil of the reader, which can be used to generate the required magnetic field to activate the remote tag. The antenna coil of the tag and the capacitor $\mathrm{C} 1$ to form a resonant circuit tuned to the transmission frequency of the reader. The voltage $U$ in the tag coil reaches a maximum due to resonance step-up in the parallel resonant circuit.

The efficiency of power transfer between the antenna coil of the reader and the tag is proportional to the operating frequency $f$, the number of windings $n$, the area $A$ enclosed by the transponder coil, the angle of the two coils relative to each other and the distance between the two coils. Generally, the operating frequencies up to $135 \mathrm{KHz}$ are used. As frequency $f$ increases, the required coil inductance of the tag coil, and thus the number of windings $n$ decreases. Because the voltage induced in the tag is still proportional to frequency $f$, the reduced number of windings barely affects the efficiency of power transfer at higher frequencies.

\section{III - METHODOLOGY}

The process involved is divided into a total of five modules that are described as follows [3]:

\section{A. Module 1 The Initial Setup}

Whenever a new book is acquired by the library, an RFID tag is attached into the book with the relevant information like, call number, accession number, book number, etc. The detailed information regarding the book is also captured in the computer database. The computer database also stores all information for individual users (patrons) of the library. Each patron is supplied with registered RFID cards. These cards carry identification data and other associated details like: address, roll no., and telephone no. etc for each patron.

\section{B. Module 2 The Login Process}

There is an administrator with special privileges who has a unique master password controlling the GUI of the RFID LMS system. As soon as he powers on the system, the first screen displays the LOGIN dialogue box. The admin then enters the corresponding password and enables the system for further usage [5].

Figure 4. Inductive Coupling: Electromagnetic Field Generated Between Tags and Reader 


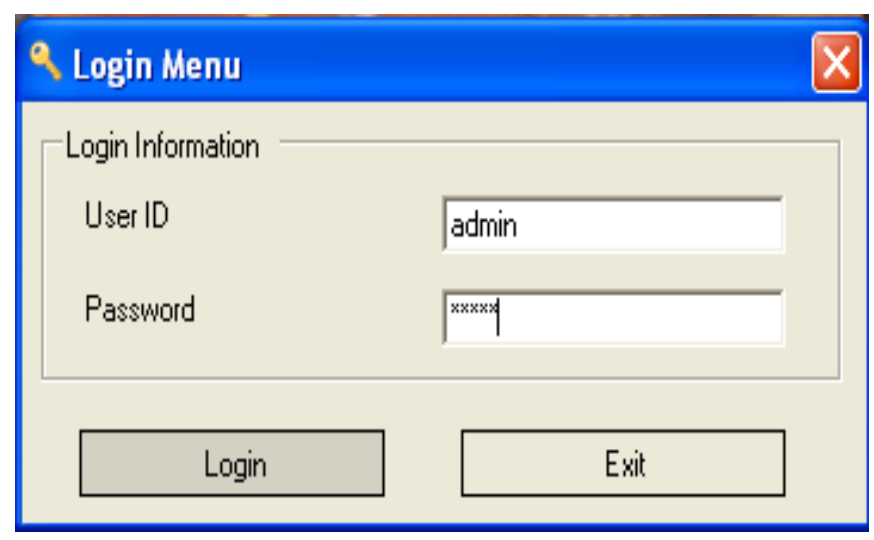

Figure 5. Login Page for Administrator

\section{Module 3 The Issue Process}

When a patron needs to get a book issued, he can get it done without any manual intervention. He simply flashes RFID card in front of the RFID reader and it automatically opens his/her login account page. He then flashes the selected books to be issued, one by one in front of the RFID reader. The computer records all these data against his name. Finally a message is displayed informing the patron that the ISSUE has been successful [9]. The user takes the books for a specified time from the library after which he has to return the books to the library.

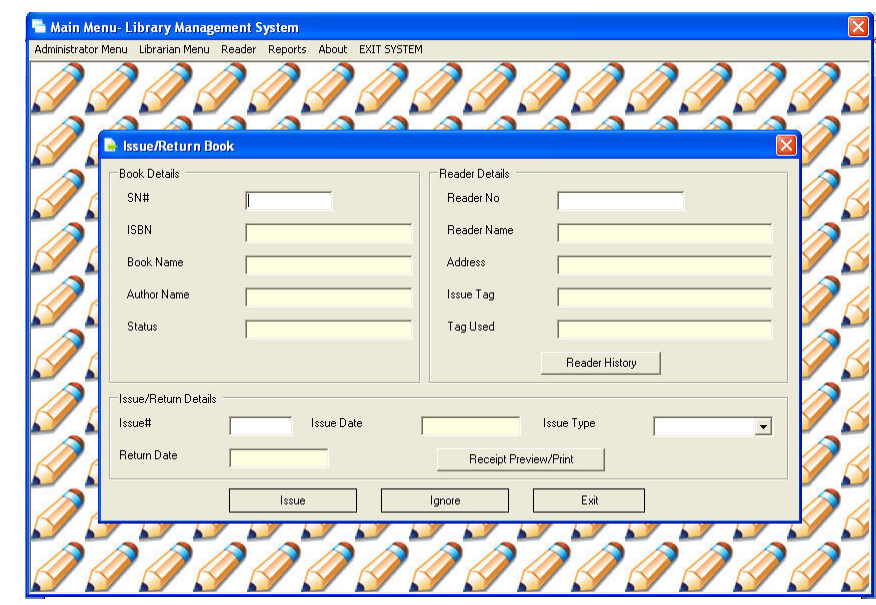

Figure 6. Issue of Books

\section{Module 4 The Return Process}

When a patron wants to return books, he simply places the books again in front of the RFID controller and the books automatically are adjusted for return against the patron's name[9].

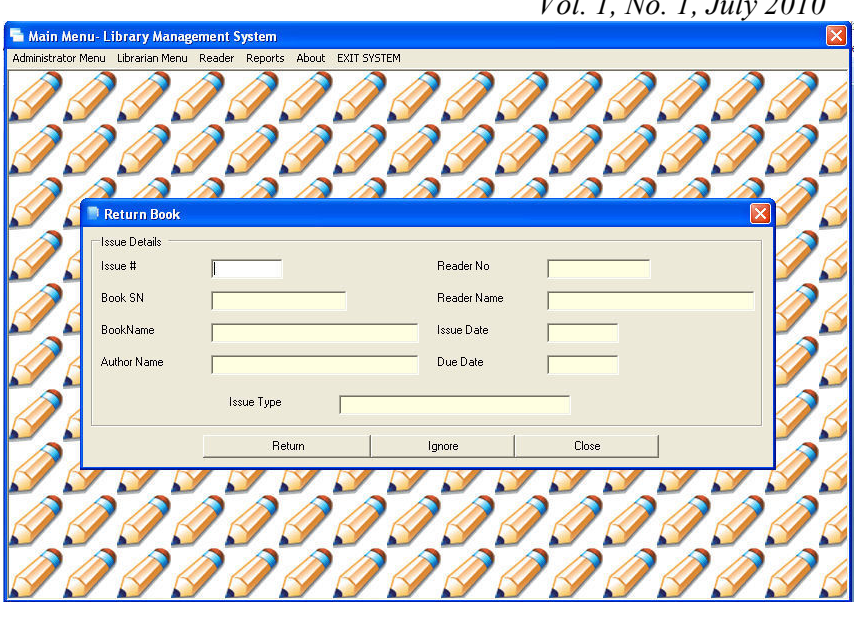

Figure 7. Return of Books

\section{E. Module 5 Fine Calculation}

When a patron wants to return books, he simply places the books again in front of the RFID controller and the books automatically are adjusted for return against the patron's name. For this the patron during the time of returning the book, clicks or activates the fine calculation button on the display area or GUI panel. The same returns the fine.

\section{IV - CONCLUSION}

Radio Frequency Identification (RFID) Systems have been in use in libraries for book identification, for self checkout, for anti-theft control, for inventory control, and for the sorting and conveying of library books. These applications can lead to significant savings in labor costs, enhance customer service, lower book theft and provide a constant record update of new collections of books.

It also speeds up book borrowing, returning and monitoring, and thus frees staff from doing manual work so that they could be used to enhance user-services task. The efficiency of the system depends upon the information to be written in tag. To yield best performance, RFID readers and RFID tags to be used must be of good quality.

\section{ACKNOWLEDGMENT}

We express our humblest gratitude to Dr. Brijesh Kumar (H.O.D IT. Dept, Lingaya's Institute of Management \& Technology) for his invaluable guidance and for defining clearly the various milestones that helped us complete the project well in time. We are highly thankful to our Project Guides Mr. RajatSheel Jain and Mr. Neeraj Maurya (IT Dept.) for their guidance and constructive criticism all during the making of this project. They pacified our intense times with their creative and innovative ideas, reinforcing our interest in the work. 


\section{REFERENCES}

[1] Karen Coyle, "Management of RFID in Libraries" ,Preprint version of article published in the Journal of Academic Librarianship, v. 31, n. 5, pp. 486-489

[2] Smart, Laura "Making Sense of RFID," Netconnect (Fall, 2004): 4-14.

[3] RFID Based Library Management System, Dhanalakshmi M, Uppala Mamatha.

[4] RFID and Organizational Transformation in the National Library Board of Singapore Paul Raj DEVADOSS

[5] RFID Technology: A Revolution in Library Management, By Dr. Indira Koneru.

[6] Roadmap for RFID Implementation in Central Library,PEC University of Technology, By Seema Vasishta

[7] Bansode, S.Y. \& Desale, S.K. (2009).Implementation of RFID technology in University of Pune Library. Program: electronic library and information systems, 43(2), 202-214.

[8] Radio Frequency Identification (RFID) Vs Barcodes, ElectroCom (Australia) Pty Ltd.

[9] Finkenzeller, RFID Handbook: Fundamentals and Applications, 2nd ed., Wiley 2003. (Chapter 3)

[10] Classification of RFID Systems,Prof. Robert Merelos-Zaragoza, Department of Electrical Engineering, San Jose State University.

\section{AUTHOR'S PROFILE}

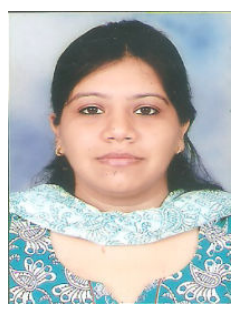

Priyanka Grover, a final year information technology student at Lingaya's Institute of Mngt. \& Tech., Faridabad, Haryana, India. Her areas of interests include database management system, data warehouse and data mining, network programming and computer networks.

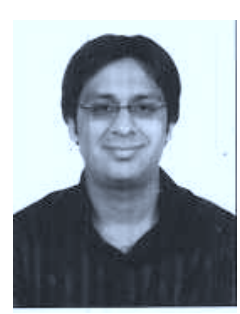

Anshul Ahuja, a final year information technology student at Lingaya's Institute of Mngt. \& Tech., Faridabad, Haryana, India. His areas of interests include computer networks, internet fundamentals, database mngt. system, and data warehouse and data mining. 